\title{
A study of the organisation and functioning of the obstetric services in a health district
}

\author{
D. S. PARKEN, P. G. HOLT, AND D. G. WILliamS
}

From Community Physicians, Lancashire Area Health Authority

SUMMARY A study was undertaken into the obstetric services of a health district to find out whether the new purpose-built obstetric accommodation was still needed and, if so, the best method for bringing it into use. If it was not required for its original purpose it was hoped that the study would reveal an alternative use. It was also hoped that the study would answer any further questions that might emerge from the investigation.

The study showed that the purpose-built obstetric accommodation was not at present required. It was recommended that the 22 obstetric beds should be used for gynaecology and that the accommodation upgraded earlier for that purpose should form part of the geriatric provision.

Early in 1974, one of us (DSP), as a newly appointed Area Medical Officer, was confronted with the problem of finding the best use for a 44-bed consultant and general practitioner obstetric unit that had been completed in 1970. This unit adjoined a small acute hospital which was a satellite of the main district general hospital in a health district with a total catchment population of 315000 .

The preliminary investigation showed that there had been disagreement between the consultant obstetricians, the former Hospital Management Committee, and the Regional Hospital Board.

The consultants felt that they had been inadequately consulted about the new unit; they had originally stated that such a unit was not viable unless other facilities were provided at the hospital, and they thought the offer of junior staff was inadequate. They said they would be prepared to work in the new unit only if these deficiencies were met. They thought it would be difficult to obtain suitable junior staff as the small number of deliveries at the unit might prevent recognition by the Royal College of Obstetricians for accreditation purposes.

The 'official' view was that consultation had indeed taken place, that the initial request for junior doctors had been met but that they had been employed elsewhere in the group, and that every time one objection from the consultants had been satisfied another was put forward.

The issue had been in deadlock for some four years and the consultant part of the new unit comprising 22 beds and the theatre remained unused. The outpatient accommodation and the general practitioner beds were, however, being fully utilised.
A project team was formed and the investigation carried out. Details were discussed with all concerned and eventually reports were made to the Obstetric Division, the Medical Executive Committee, the District Management Team, and the Area Health Authority.

\section{Details of the study}

The team considered that the following factors were relevant:

The birth rate was declining.

The postpartum stay in hospital was shorter.

More women were reaching the childbearing ages. The number of hospital deliveries was increasing. A new town was being developed in the health district.

The future birth rate could not be predicted with certainty.

A preliminary discussion with the obstetricians revealed no desire for additional obstetric beds in any part of the district. Their opposition to the newly built obstetric unit was on the following grounds:

The obstetric services would be further subdivided. Blood would not be immediately available in an emergency.

Pathology services would be remote.

Radiological services would be restricted.

Paediatric staff would be remote.

The establishment of the junior medical staff would have to be increased to the levels recommended by the Royal College of Obstetricians and Gynaecologists. 
Table 1 Population of health district

\begin{tabular}{|c|c|c|c|c|c|}
\hline District & $\begin{array}{l}\text { Population } \\
1971 \text { census }\end{array}$ & $\begin{array}{l}\text { Population } \\
\text { mid 1974* }\end{array}$ & $\begin{array}{l}\text { Increase or } \\
\text { decrease }(\%)\end{array}$ & $\begin{array}{l}\text { Population } \\
\text { projection } 1981 \dagger\end{array}$ & $\begin{array}{l}\text { Increase over } \\
1971 \text { census }(\%)\end{array}$ \\
\hline $\begin{array}{l}\text { Local Government district } \\
\text { A } \\
\text { B } \\
\text { C }\end{array}$ & $\begin{array}{r}135133 \\
85045 \\
77696\end{array}$ & $\begin{array}{r}132000 \\
90500 \\
82300\end{array}$ & $\begin{array}{r}-2 \cdot 4 \\
+6 \cdot 4 \\
+5 \cdot 9\end{array}$ & $\begin{array}{c}146000 \\
131400^{*} \\
80500\end{array}$ & $\begin{array}{c}8 \cdot 04 \\
54 \cdot 5 \\
3 \cdot 6\end{array}$ \\
\hline Health district & 297874 & 304800 & $+2 \cdot 3$ & 357 900* & $20 \cdot 15$ \\
\hline
\end{tabular}

-Registrar General's provisional estimate

+Department of the Environment

Good junior medical staff would be difficult to recruit as it was doubtful if the experience to be gained by each doctor would be adequate to meet the requirements of the RCOG accreditation scheme which recommends a unit with a minimum of 1500 deliveries per year (Royal College of Obstetricians and Gynaecologists, 1973).

\section{Available data}

The actual populations in 1971 and 1974 and the projected population for 1981 are shown in Table 1. The team viewed with scepticism the projected population figure of 358000 for 1981 and rounded this down to 350000 . This was subsequently justified by revised official estimates which now suggest that a population of 350000 is not likely to be attained before 1990 .

The number of obstetric beds in use in the health district in 1974 is shown in Table 2, but 20 of the beds in Hospital $\mathbf{R}$ were closed for most of the year without causing much difficulty. The number of births notified in the district in 1974 was 4440 and of these only $386(9 \%)$ of babies were delivered at home.

Table 2 Obstetric beds in 1974

\begin{tabular}{lccc}
\hline Hospital & $\begin{array}{l}\text { Consultant } \\
\text { beds }\end{array}$ & $\begin{array}{l}\text { General } \\
\text { practitioner beds }\end{array}$ & Total beds \\
\hline $\mathbf{R}$ & 48 & 9 & 47 \\
$\mathbf{T}$ & 53 & $\frac{9}{53}$ & 22 \\
Total & 101 & 31 & 132 \\
\hline
\end{tabular}

The geography of the district is important as the area is roughly bisected by a river. The northern part is a complete local government district (District A) with a population in 1974 of 132000 ; the southern part comprises two local government districts (Districts B and C) with populations of 90500 and 82300 . In spite of limited bridges about two-thirds of the population of District B find it easy to travel to the centre of District A where the district general hospital (Hospital R) is situated. Hospital $\mathbf{S}$ is a mainly acute hospital some two miles distant. Both these hospitals have consultant obstetric and gynaecology beds and special care baby units; the blood bank is in Hospital $R$.
District $\mathrm{C}$ is about 11 miles from District $\mathrm{A}$ and it was here that the obstetric unit we were investigating was located in Hospital T. The journey between these hospitals can be time consuming.

The new town includes part of all three local government districts and the projected population of 350000 by 1981 was based largely upon the expansion planned by the development corporation. Large new housing schemes were being planned within the boundaries of all three local government districts although the earliest development was taking place in Districts $B$ and $C$ and the population was currently declining in District A. As development proceeds the population will expand still further.

Plans for a new 920-bedded district gener重 hospital had reached tender stage in 1973, bu the original concept has been rejected and furthers moves were being made to replan the hospital io $\vec{\varphi}$ phases. The site is in District $\mathbf{A}$ about one mile from. $V$ Hospital S which, it was proposed, would continuo as part of the total hospital provision, but with a changed role. It was generally thought that Hospital $\mathrm{R}$ would close or perhaps become a community hospital, but no final decision had been made. As the final political decision was unknown we felt that our investigation should be aimed primarily at resolving the current problem and that possible future developments should be a secondary consideration.

This turned out to be the correct course of action as the new hospital project was divided into three phases with obstetrics and gynaecology in phase 3 . Only phases 1 and 2 have been approved so far and building is proceeding without provision for maternity, special baby care, or gynaecological services - thus leaving a further problem which was dealt with later as a separate issue.

Although we examined patient flow patterns we felt that these gave only limited help as patients had $N$ no real alternative to accommodation in Hospitals $R$ and $S$ when needing consultant care. Of the 4054 hospital births, $1400(34 \%)$ were delivered by mothers $\omega$ whose place of residence would suggest that they might find Hospital T more convenient than Hospital 6 $\mathbf{R}$ or $\mathbf{S}$.

.


The recommended national norm of 0.5 obstetric beds per 1000 population would suggest a need for 157 beds with the 1974 population of 315000 and would require 175 beds for the projected population of 350000 . But clearly these norms were irrelevant as during 1974 the district had coped adequately with only 112 beds in effective use.

We developed a more realistic figure, shown in Table 3.

Table 3

\begin{tabular}{lll}
\hline Variable & Symbol & Level assumed \\
\hline Population & $\mathrm{P}$ & $(315000)$ \\
Birth rate per 1000 & $\mathrm{~B}$ & $(14 \cdot 6$ per 1000) \\
*Proportion hospital confinements & $\mathrm{h}$ & $(1 \cdot 0)$ \\
Duration of stay in hospital & $\mathrm{d}$ & $(6 \cdot 2$ days $)$ \\
$\begin{array}{l}\text { Proportion of beds occupied } \\
\text { Beds required }\end{array}$ & $\mathrm{b}$ & $(0 \cdot 75)$ \\
Then $\mathrm{R}_{1}=\mathrm{P} \cdot \frac{\mathrm{B}}{1000} \cdot \mathrm{h} \cdot \frac{\mathrm{d}}{365} \cdot \frac{1}{\mathrm{~b}}$ & $\mathrm{R}_{1}$ & \\
\end{tabular}

*Department of Health and Social Security Welsh Office (1970)

A further number of beds will be required for antenatal care and for postnatal patients who require longer treatment. A provision of $20 \%$ extra beds for this purpose was proposed. Thus the total number of beds required, $R_{2}$, is given by:

$R_{2}=R_{1}(1+E)$ (where $E$ is assumed to 0.20 ).

This formula yields 125 beds required for the 1974 population and 139 beds required for the projected population of 350000 .

The number of beds available in 1974 was 132 so we recommended that this number should not be increased and that the 22 beds at Hospital $T$ available for this purpose should be allocated to other uses. This recommendation was accepted and the Community Health Council welcomed the report.

\section{Discussion}

In coming to our conclusion we had deliberately set out to find a reasonable obstetric bed requirement for the district using certain criteria that would overestimate the number so as to balance any underestimation that might be caused by unknown factors.

We assumed there would be $100 \%$ hospital deliveries although in 1974 only $92 \%$ were delivered in hospital. We assumed a birth rate of 14.6 per 1000 population although we confidently expected this would decline (which it did to 13.4 by 1975). We used a projected population figure which we knew to be too high and which we now know to be more applicable to 1991 than 1981 . We were aware that there would be more women of childbearing age so that even with a declining birth rate, the number of deliveries would be likely to increase in the late 1970s or early 1980 s. Predictions as to precisely when this would occur appeared to us to be unreliable.

\section{GYNAECOLOGY}

The consultant obstetricians and gynaecologists made comments which led us to examine the needs for gynaecology beds.

An analysis of available gynaecology beds indicated there was a provision of 0.21 beds per thousand resident population in the district and 0.19 beds per thousand for the planned population. The regional norm for this specialty is 0.25 beds per thousand population served.

The waiting list for admissions expressed as a percentage of annual deaths and discharges was $38.2 \%$ - the highest in the area and double the regional average.

When the new maternity unit at Hospital $T$ had been completed, the ward that had previously been used for general practitioner maternity patients was upgraded for 19 gynaecological patients but then was not used for this purpose as elderly patients from a nearby geriatric hospital had to be transferred to allow an upgrading scheme there to proceed.

The eight beds used for gynaecological purposes in Hospital $\mathrm{T}$ formed part of an otherwise general surgery ward. The intention had been that these beds would become available for surgical patients upon being vacated by the gynaecology patients.

Apart from the smaller specialties which could not sensibly be isolated at Hospital $T$, the largest deficiency in district specialties was in geriatrics where there were 305 available beds compared with an immediate need for 409 beds based upon the national norm.

The elderly severely mentally ill patients in this part of the district would be assisted by the building of a new unit adjoining Hospital $T$ which it was planned would provide 56 beds and 50 day places.

The greatest need was, therefore, shown to be in beds for geriatric patients.

\section{Recommendations}

The following recommendations were made for making use of the vacant and other accommodation:

1. The 22 beds in the new obstetric unit together with a theatre should be used for gynaecology. This would give the gynaecologists three more beds than in the original proposal which has been temporarily held in abeyance while the geriatric hospital was being upgraded.

2. The 19 beds in the upgraded ward, originally set aside for gynaecology and now temporarily used by elderly patients, should be permanently used for geriatric patients. 
3. The eight gynaecology beds within the general surgical ward should be absorbed for general surgery as originally proposed.

These recommendations were unanimously accepted by the Medical Executive Committee and appropriate Cogwheel Divisions, the District Management Team, and the Area Health Authority.

The 19 beds which the geriatricians took over have been successfully used and thereby filled a gap in the service as far as this part of the district was concerned.
Reprints from D. S. Parken, Area Medical Officer, Lancashire Health Authority, East Cliff Offices, Preston PR1 3JN.

\section{References}

Department of Health and Social Security Welsh Office (1970). Standing Maternity and Midwifery Advisory Committee: Report of the Sub-Committee on Domiciliary Midwifery and Maternity Bed Needs. HMSO: London.

Royal College of Obstetricians and Gynaecologists (1973). Report of the Committee on Staffing Structure of Departments of Obstetrics and Gynaecology. 